\title{
The future past of travel: adventure tourism supporting humans living on the edge of existence
}

\author{
Daniel William Mackenzie Wright
}

\begin{abstract}
Purpose - By drawing on current reports, this paper positions that Homo sapiens could in the near future be faced with an increasingly uninhabitable planet. It emphasises the importance of adventure tourism and its associated activities as a means of supporting individuals to develop more outdoor survival skills.

Design/methodology/approach - This study applies a scenario narrative approach in exploring and presenting potential future ideas. The significance of narratives lies at the essential examination of current trends and drivers that could be shaping future scenarios. This paper, through the exploration of past and current trends supports the researcher in presenting future views. The scenario narratives in this research are established via desk-based research and inspection of academic journals, industry reports, ideas and knowledge.

Findings - If society is pushed to the brink of extinction due to a catastrophic event(s), people will require survival skills, similar to those shared by our hunter-gather nomad ancestor. Thus, this paper highlights the value and importance of the industry in encouraging soft and hard outdoor adventure in the coming years. It recognises how different adventure travel activities can support people in rekindling with our more basic instincts and ultimately, surviving in different natural environments.

Originality/value - This paper offers original theoretical knowledge within the adventure tourism literature. Offering original consideration to the value of exploring the past as a method of understanding the future, the paper presents an original spectrum of soft and hard skills-based adventure tourism activities.
\end{abstract}

Keywords Climate change, Adventure tourism, Future travel, Doomsday scenarios, Human extinction, Tourism futures

Paper type Research paper

\section{Introduction}

Society is never far away from presenting visuals and ideas of humanity living on the edge of existence. Climate change, natural disasters and or human induced catastrophic events, all potentially leave us living on the brink. Likewise, humanity is promised that something will come to our savour, technology, evolved human beings, extra-terrestrial beings, a deity, or your government, all coming to our savour and dragging us through the challenging times ahead. How much faith do you place in others to protect you in times of difficulty, or matters of life and death? If you do not feel that you have the capabilities for individual survival, then maybe it is time to consider alternative activities during your leisure and holiday time. In the event that you are forced to fend for yourself, having some of the survival skills that were common with our earliest of ancestors could prove useful.

Homo sapiens can explore the origins of human movement and travel by revisiting our huntergather ancestors. The original nomadic characteristics involved moving and exploring new lands in search of basic survival necessities, such as food, water and shelter. Gradually over time, our
Daniel William Mackenzie

Wright is based at the Division of Tourism, Hospitality and Events, University of Central Lancashire, Preston, UK.
Received 17 January 2021 Revised 11 May 2021 Accepted 21 May 2021

(C) Daniel William Mackenzie Wright. Published in Journal of Tourism Futures. Published by Emerald Publishing Limited. This article is published under the Creative Commons Attribution (CC BY 4.0) licence. Anyone may reproduce, distribute, translate and create derivative works of this article (for both commercial and non-commercial purposes), subject to full attribution to the original publication and authors. The full terms of this licence may be seen at http:// creativecommons.org/licences/ by/4.0/legalcode 
ancestor laid the foundations to what we are more accustomed to today, living in communities, with shared values and supporting one another, with services and facilities to cater for our basic human need(s). However, unlike the past, Homo sapiens have evolved to become a rather unique species. Today, we have established a globally connected world of travel and communication. Our desires, motivations and consumption for experiences and knowledge are vast and diverse. Within these, travel and tourism had moved from the original needs of food and water, to more complex requests, as we now find ourselves travelling the globe for leisure purpose, driven by luxury, novelty, entertainment, education and so much more. However, amongst such prosperous developments, society and humans are potentially on the tipping-point of being at their most vulnerable. The industrial world is established on communities, based on trust and support. In the event of a natural disaster that leaves millions (even billions) of people in desperation, would our more hunter-gather instincts come to the fore? Would our governments support us, as many historical examples prove otherwise? Would our evolutionary instincts, survival of the fittest, therefore, take over and ask yourself, what survival skills do you have? These are difficult questions, but important ones to consider. What if our world was plunged into darkness and that all the warning signs started to become real? How prepared are we, to go out into the natural environment and survive? Are we capable of hunting, finishing and making tools to keep you and your family alive? Of course, for many people such doomsday ideas are a thing of fiction and history, it is only when such ideas become a reality, that society and individuals often react and start making changes. The recent COVID-19 pandemic has certainly been a shock that many people never expected they would have to live through in their lifetime.

If a doomsday scenario became a reality, humans across the globe would be impacted differently (due to the level of living and working infrastructure that currently exists and our reliance on facilities and services to maintain us for food, water and health). Across the globe communities live differently, in reference to their social existence and how they operate within the natural environment. Thus, any event that forced us to change would have different levels of significance and impacts for different people across the globe (some would be better prepared and others less). However, in such life changing scenarios, across the globe, people could be potentially forced to live and travel like that of our hunter-gather ancestors. Some communities would be better prepared (to survive off the land), but many of us no longer have the skills to do so. Nevertheless, we could be better prepared, and travel and tourism can pave the way for equipping society and its individuals in the event of such Armageddon based scenarios.

Adventure tourism and the activities involved, provide tourists with experiences that are more accustomed to our ancestors. Adventure travel takes place in our natural world and depending on the level of risk and danger of the activity, it transpires in challenging environments and conditions. With soft to hard forms of adventure activities, people can develop the required knowledge and skills that will increase their survival if forced to live in the wild. Therein lies the focus of this paper, the value of adventure tourism in developing a society (or individuals) that can reconnect and survive in nature. Importantly, it does so as a means of stressing that in the event of catastrophic change to the environment, society might be forced to adapt.

Ideally, a doomsday scenario will not emerge, but it could. How soon and quickly is up to debate. In order to present such ideas, this paper presents two future scenarios (written narratives). One scenario focuses on a more progressive decline in our natural environment, and the second focuses on a more instant and sudden decline of societal current systems. Each scenario justified by presenting and drawing on a range of evidence. Ultimately, in both scenarios, humanity is on the brink with only a few hundred thousand Homo sapiens left. Here, the future past of travel contemplates how "the last of us", will return to more huntergather characteristics, where travel is less about less and more about survival. This paper offers original value to the importance of adventure tourism and its related activities. Ultimately, it continues to shine a light on the value of past and present-day trends as a means to not only envisage the future, but how they are part of the entangled and developing nature of our social and natural evolution.

PAGE 2 | JOURNAL OF TOURISM FUTURES $\mid$ VOL. $\mathbf{m}$ NO. 2021 


\section{Methodology}

As noted by Lee (2012, p. 2), foresight, could be societies most effective tool for understanding our evolution and ultimately should be applied as a method for long-term survival and mastery of our environment. Lee suggests that humans have now amassed enough knowledge of our world that we can produce real, valid and valuable foreknowledge offering anticipatory predictions of future conditions. Therefore, future research is now at the forefront of many research papers. Gladwell (2002) recognises the importance of futures research as a method to consider the development of society and can be done by examining "tipping points". These are achievable by exploring trends and changes, identifying signs, technological advancement and social movements (Gladwell, 2002). Mannermaa (1991) suggests that the identification of tipping points is fundamental to the evolutionary paradigm from futures studies. Yeoman and McMahon-Beattie (2020, p. 2), note that, "from a historical perspective, eras are incremental and continuous phases in the development of tourism with relative coherence and stability". Therefore, specific eras (or turning points) can be identified from one year to another (Li and Petrick, 2008). According to Hobsbawn (1995), the future is a replication of the past; Yeoman and McMahon-Beattie $(2016,2020)$ note that if this is the case, then it should be possible by analysing the past to inform the future.

Descriptive futures research can be grounded on the notion of historicism, the idea of the general nature of societal development (Propper and Miller, 1983). According to Miles (1978, p. 68) historicism states the idea of predicting the future on the basis of supposed laws of historical evolution, whose operation could be projected forward in order to shine a light on future views. This paper, therefore, draws on ideas of the past in order to present ideas for the future. In order to do this, the research takes a scenario narrative approach in its method of presenting future ideas. Heijden et al. (2002) suggest that "scenario planning is a process of predicting multiple, plausible and uncertain futures". The valuable application of scenarios is noted by Rasmussen (2005), who suggests that scenarios offer flexible methods to assimilate different ideas, thoughts and feelings into holistic images. Thus, providing the required context and meaning of possible futures (Rasmussen, 2005). Moreover, a narrative approach allows the scenario designer to present a holistic view(s) of the future. Consequently, narrative writing is recognised as an effective method of presenting future ideas, especially when they coincide with written stories that are engaging and informative (Lindgren and Bandhold, 2009). According to Polkinghorne (1988) the narrative method precedes the more logical and pragmatic hard-science epistemologies applied to human understanding and sense-making, because its origins can be traced to the earliest forms of pervasive human experience.

The overarching importance and contribution of scenario methods is not down to their ability to predict the future, but in offering insights into the present (Rotmans et al., 2002). As Yeoman (2012) suggests, the significance of narratives lies at the essential examination of current trends and drivers that could be shaping the future scenarios. Thus, this paper, through the exploration of current trends, presents future views. A fact-finding method of analysing secondary data is applied, exploring information and knowledge relevant to the subject areas. The scenario narratives in this research are established via desk-based research and inspection of academic journals, industry reports, ideas and knowledge (van Notten et al., 2003).

Evidently, there are some limitations to the research method. The scenarios presented here are somewhat deterministic and hypothetical, even if grounded by research. Deterministic methods often present a few scenarios as is the case here. However, the future is uncertain and consequently, this draws limitations to the ideas presented. The practicality of hypothetical scenarios is they offer more flexibility, both in design and timeframe. As noted by Rasmusen (2005) scenario narratives are only as good as the underlying idea that is being conveyed. Thus, the ideas presented should find the correct balance, not being too loose or to restricted or the story could reveal its inadequacies. Importantly, the message coming out of the scenario should be compelling to the people who will read it and take away the important message on offer (and in some circumstances implement necessary changes). Other limitations can occur when scenarios are too dry or lacking emotional dialogue. Thus, focus should be on the strengths of scenario writing and 
their ability to "appeal to the human being as a whole creature: sense, emotions, thoughts, behaviours and so on" (Rasmusen, 2005, p. 245). Thus, the two narrative scenarios presented here, whilst might not be the future, they try to offer future depictions based on current evidence. Through the use of creative storytelling, the scenarios aim to elicit a rich imagery of thoughts, feelings and ideas to help readers to be aware and engage in strategic thinking, conversation and preferably, changes in attitudes and behavioural.

\section{The end times}

"Pessimistic scenarios might see natural or manmade disasters leading to widespread breakdown of social order, even civilisation and the loss of most of the human population - a grim, postapocalyptic world. Even so, humans would likely survive, scavenging society's remains, Mad Maxstyle, perhaps reverting to subsistence farming, even becoming hunter-gatherers. Survival sets a pretty low bar. The question isn't so much whether humans survive the next three or three hundred thousand years, but whether we can do more than just survive" (Longrich, 2020). This quote sets a vivid image of a potential future and ultimately, a vision that this paper explores in more detail in order to set the parameters around the value of preparedness and how adventure tourism can play its part in the eventuality of any above scenario becoming a reality. It must be stated that the discussions in this section draw on evidence and ideas that see a more dystopian view of the future. Clearly, alternative futures can transpire (and hopefully will), but they do not fit the focus and narrative of this research.

A key question then for the reader, is if humans will eventually reach the end time, when will it be? There are no simple answers to this question, just ideas and propositions of how and when we could. Likewise, there are many depictions of showcasing humanities continued existence long into the future, be it on planet Earth or by exploring the Solar System and beyond. Dystopia and desperate visions of a deadly end are never far away from fiction and non-fiction literature and visuals. Society is frequently exposed to apocalyptic scenarios of catastrophic climate change impacts, human (nuclear) wars and new technologies such as robots taking control. Drake (2017) notes, in the last half-billion years, life on Earth has been nearly wiped out five times due to events such as climate change, an intense ice age, volcanoes and a space rock smashing into the Gulf of Mexico 65 million years ago, obliterating the dinosaurs and a bunch of other species. These events are known as the Big Five mass extinctions, and evidence is now pulling us towards the suggestion that we are on course for the sixth mass extinction (Drake, 2017). Scientific coverage is reporting that the depletion of our natural environment and the impacts this is having on species is potentially leading us to another mass extinction. For the first time since the dinosaurs (65 million years ago) humanity is facing a global mass extinction of wildlife due to our misuse of natural resources. Humans are threatening natural habitats, and subsequently, pushing species to the brink of extinction (Barrett, 2016). This idea is supported by Ceballos et al. (2015) warning that Earth is entering the sixth mass extinction. Suggesting, if humans do not act now, in the next 50 years we will be living in a completely different world, a world that will challenge humanity like never before. At the Global Catastrophic Risk Conference at the University of Oxford, Sandberg and Bostrom (2008) in an informal survey of different global catastrophic risks, experts identified a 19\% chance of human extinction by the year 2100 .

So, will our species eventually go extinct? According to Longrich (2020) the short answer is yes, as fossil records provide evidence that almost all species that ever lived, over 99.9\%, have gone extinct. However, our species is somewhat unique, and arguments also suggest that humans could live forever, be it as an evolved form of Homo sapiens (possibly part robot and Al), or that we could save ourselves by moving beyond Earth and into space. However, as suggested by Longrich (2020) unlike small, cold-blooded turtles and snakes that can last months without food, humans have vulnerabilities; we are large, warm-blooded animals that do not handle ecological disruptions well. As bigger animals with fast metabolisms humans require a lot of food, constantly. Thus, catastrophes impacting our natural planet (key to our survival) such as climate change and global warming, ice ages or the impact of winter after an asteroid collision can cause disruptions in the

PAGE $4 \mid$ JOURNAL OF TOURISM FUTURES $\mid$ VOL. $\mathbf{m} \mathbf{m}$ NO. $\mathbf{m} 2021$ 
food chain, ultimately leaving humans in a vulnerable position. Whilst we are vulnerable, we are also potentially resistant to extinction because of our uniqueness to change and ability to adapt. As Longrich (2020) suggests, humans are a strange species, we have become widespread, abundant and adaptable, which could give us encouragement that we will be around from some time to come. Organisms with vast geographical existence are likely to do better if met with catastrophes, and we have learnt to live in a range of different geographical habitats.

Additionally, humans are currently in abundance, at present there over 7 billion of us. However, the most important element of our adaptability unlike any other species is our learnt behaviours, not just through our DNA, but what we have learnt by means of culture. Humans do not take generations to change their genes; humans use intelligence, culture and manmade tools to adapt their behaviour in years, even minutes. Cultural evolution is not only seen to be faster than genetic evolution, but different, as natural selection has seen us become an animal that is not limited to our environment, but an animal with the capacity to (re)shape it, to meet our needs and demands (at any given time). Such an adaptability can make us our own worst enemies, too clever for our own good, as changing the world does not mean for the better (as it can lead to dangerous realities, such as wars, pandemics, pollution, climate damage etc. . .).

Rifkin (2013) asks the question, what can we do to prepare for a doomsday scenario and offers a list of suggestions that including some of the following: creating worldwide stockpiles of grains, food reserves, wild plant species, seeds and gene banks to safeguard genetic diversity. Strive and invest in new scientific technology which provides increased accuracy to predict and withstand major environmental threats and increased international cooperation to reduce nuclear proliferation. Rifkin even suggests selecting a small number of people to keep protected in a refugee sanctuary with enough supplies to last for years to combat against human extinction. Likewise, develop better provision to detect, prevent and halt emerging pandemic infectious diseases that could spread rapidly across the globe. Reports continue to discuss how society contemplates and is preparing for such doomsday predictions. However, suggestions rarely consider improving and preparing Homo sapiens on a more individual level. Many of the suggestions are driven by a modern mentality, a top-down approach. Solutions and ideas where society expects institutions and nation states to look after them. Natural disasters even throughout the 20th century have clearly highlighted not only our vulnerability to disasters, but the lack of planning, support and recovery from them on behalf of national and global organisations. The questions that arise are, do you think your government will save you and if not, then who will? Are you prepared to safe yourself? Individuals go to different lengths when preparing for the future. Some live on a day to day basis, whilst others go as far as creating luxury bunkers in preparation to survive any calamity and or collapse across society (Garrett, 2020). However, changing one's mindset and attitude and placing money and energy into bunkers to prepare for a potential doomsday scenario is arguably beyond the physical and mental means of many people. However, individuals could still take some measures to increase their knowledge of basic human survival skills (beyond watching Bear Grylls on television). Significantly, the key message driven in this research, does the adventure tourism industry offer potential as a way forward for many people keen to learn more about living and surviving in the natural world?

\section{Adventure tourism and tourists}

The tourism industry has the potential to encourage tourist to spend more time outdoors, reengaging with the natural environment. Adventure, outdoor and recreational tourism activities encourage people to move beyond their comfort zone, to more unknown destinations, environments and to participate in activities that are more demanding (emotionally and physically) from that which people are required to express in their day to day existence. According to the Adventure Travel Trade Association (2021) "adventure tourism is a tourist activity that includes physical activity, cultural exchange, or activities in nature." Martin and Priest (1986) note that the key features of adventure tourism are risk and competence. Likewise, Ewert and Hollenhorst (1989), in defining adventure tourism, suggested that a certain degree of danger and 
risk combined with a search of competence are a key ingredient, as it aims to provide tourists with a true sense of adventure. Many authors highlight how adventure was recognised as the main motivating factor for tourists to participate in adventure recreation (Weber, 2001; Dowd, 2004; Lipscombe, 2007). Hall and Weiler (1992) suggest that tourists' primary motivations to participate in adventure recreation activities were to be in contact with nature, stimulation, self-actualisation, adventure and social contact. Schlegelmilch and Ollenburg (2013) note that risk, fear and thrill are the primary factors motivating tourists to partake in adventure activities. Pidgeon et al. (2003) see the value and importance of being in contact with nature and the sociability of activities.

The adventure tourism market by type can be categorised as hard, soft and others; activities include, land-based, water-based and air-based. Whilst the tourist participating can comprise of solo, friends / groups, couples and families, and age groups range from below 30 years, 30-41 years, 42-49 years and 50 years and above, and sales channel include travel agents and direct (Chouhan et al., 2019). The global adventure tourism market in 2018 was valued at $\$ 586.3$ billion and by 2026 is projected to reach $\$ 1,626.7$ billion (Chouhan et al., 2019). Figure 1 provides an overview of age and level of enthusiasm, with four segments. It is suggested that low specialism adventure travellers are mainly concerned in a range of soft adventure tourism (see Figure 2) activities, and they like to alternate it with other activities, like cultural excursions, and these groups are the largest segment (CBI, 2021).

The past few years has seen substantial growth in the adventure tourism industry. More recently, travellers are becoming increasingly interested in visiting undiscovered destinations. This has been supported by important upsurge in government initiatives in the form of private and public partnership to promote adventure tourism. However, the niche tourism market continues to limit itself due to the potential risks involved, including the impacts of unpredictable weather conditions (Chouhan et al., 2019). However, as more tourists participate in adventure travel, the likelihood of more people seeking novelty and greater adventure could see more specialist travellers seeking greater desires for increased risk factors associated with the different types of soft and hard activities. Nikolova, regional director for Europe and Central Asia at the Adventure Travel Trade Association (ATTA), recently told a virtual audience that the COVID-19 crisis could become an opportunity for investing in new visitor expectations, which will see more people keen to be outdoor and active. Nikolova suggested, "outdoors businesses and destinations have a chance to flip the crisis into an opportunity by investing in innovation, infrastructure, gear, community building and

Figure 1 Adventure travel segments: levels of enthusiasm and age

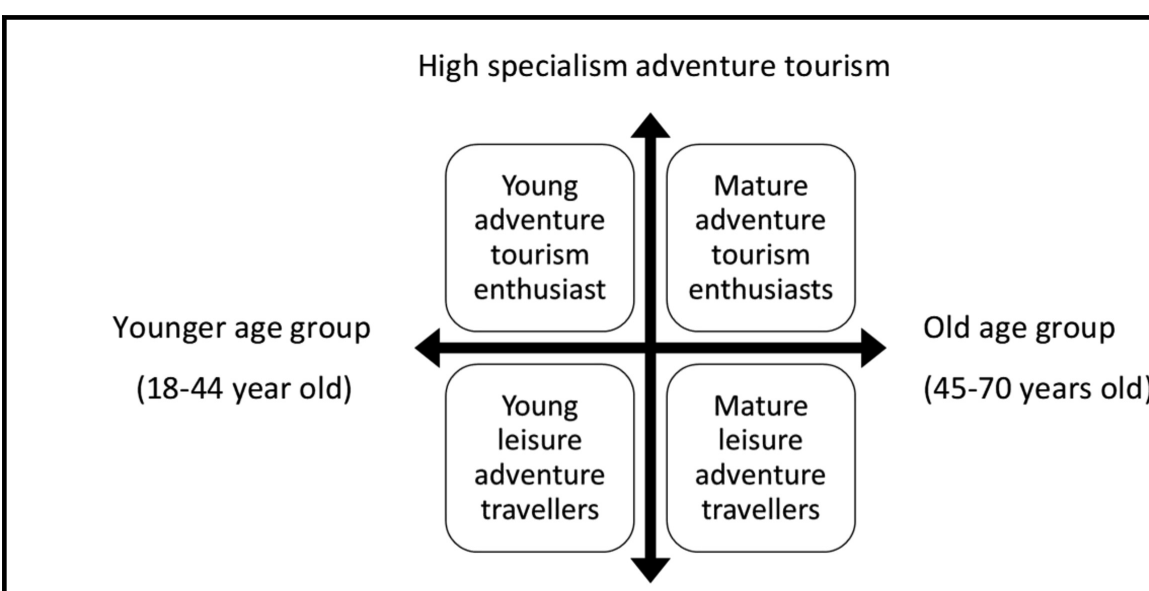

Low specialism adventure tourism

Source(s): Adapted from CBI (2021) 
Figure 2 Spectrum of hard and soft forms of adventure travel

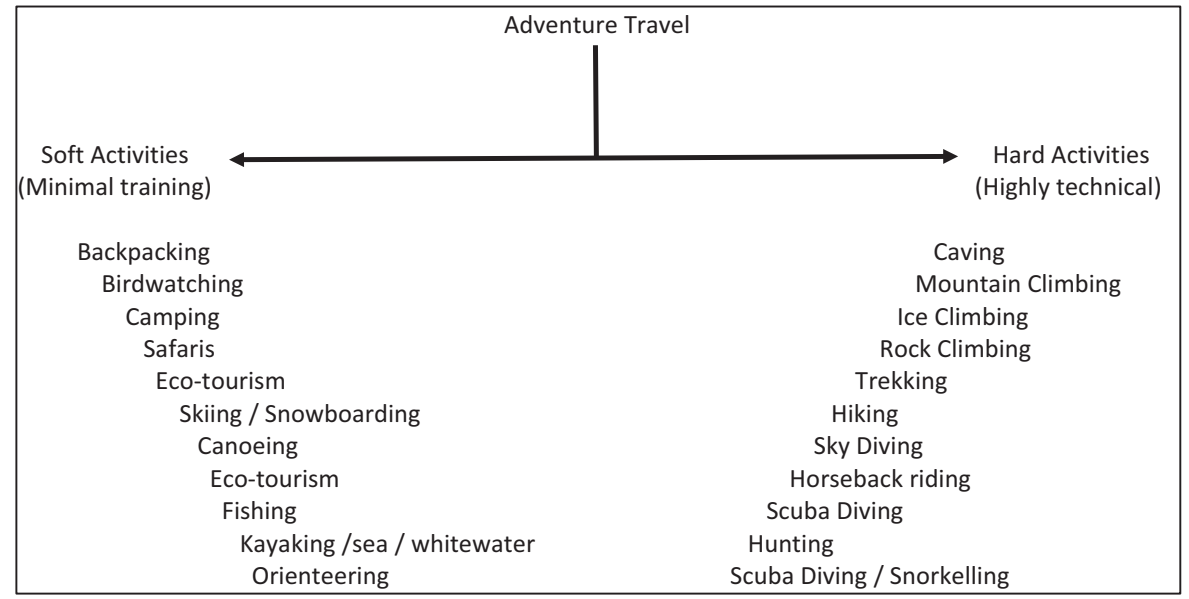

Source(s): CBI (2021) and Tourism Notes (2021)

redesign that will position them to be among the winners when markets recover" (Ross, 2020). In the past, adventure travel was deemed as risky, hard-core and niche, and associated with skydiving, mountain climbing or paragliding (but this area only constitutes $10 \%$ of the market). However, travellers could look to expand their world view, pursue new and unique challenges, spend more time in nature and feel better mentally and physically (Ross, 2020). There should be no surprise in the urge for people to want to engage with outdoor activities. Our modern techno driven society has arguably pulled us away from the outdoors, driven us indoors, creating a more screen (mobile phones, TVs and computers) orientated society. However, living outdoors, moving across lands and surviving off the natural world are deep-rooted in our Homo sapiens instincts. Thus, the parallels with outdoors tourism activities can be seen in the lives of our earliest of ancestors.

\section{The movement of people: hunter-gatherers, Homo sapiens and modern society}

Travel is not something new to us; it has evolved throughout time, with its roots located to our earliest of ancestors. The motives and (cap)ability to move with ease and tranquillity has transformed over time. "Scarcely, 15,000 years ago, humankind consisted of a mere few thousand individuals. Scattered across the globe, these nomads migrated in search of food, led by changes in climate and the seasons. Four million years earlier, their distant ancestors did not do things any differently. So, it is safe to assume that nomadic instincts are deeply rooted in Homo sapiens genes" (van der Tuuk, 2020). Travel once cantered on seeking new lands and peoples, to expand human knowledge, much with the aim of discovery (for food, medicines and resources). Travelling out of necessity still exists today for humans engulfed in war. However, for many, (domestic and international) travel forms part of an experience that is centred on satisfying one's pleasures and interests, rather than for survival. Evolution has got us to where we are today, and with our knowledge in science, technology and discoveries in new medicines, society has been able to better understand and even manipulate the evolutionary process. Humans now have the power to unify genes, science, technology and culture, in order to best match us to our environment. However, this is not protection against the greater forces of Mother Nature. Where we end up as a species of course, is a more complex question.

Our future is no guarantee and neither is our continued longevity on this planet. If humans do eventually come to a time and place that only a few hundred thousand people remain, holding on, trying to avoid extinction, then could we look back to the skills of our ancestors as a means to 
continuous revival (or at least to drag out our existence)? Some communities today still hold survival skills that many of society do not. For example, the "Hadza people of Tanzania rely on hunting wild game for meat, a task that requires great skill in tracking, teamwork, and accuracy with a bow and arrow" (National Geographic, 2021). Today, these communities have survival characteristics similar to our earliest of ancestors, such as those shown by Hunter-gatherer groups (Groeneveld, 2016). Who roamed the lands, battled the seasons and adapted to learn and survive in different climates. Unlike what we experience today, establishing long-term settlements was impractical, and the majority of hunter-gatherers can be seen as nomadic (National Geographic, 2021). Currently, there are very few hunter-gather communities that exist. The Hadza people of Tanzania are one of the last groups to live and maintain the origins of the tradition hunters (National Geographic, 2021).

Today, humans have now become more than our biological evolution. Humans are culturally relative and have evolved to become an incredibly unique species. For many, we are now far removed from our ancestors; we live in modern industrialised societies where people live together in a range of rural and urban environments. We have at our power the ability to change our environment to meet our needs. Humans have advanced industry and technological systems. Humans have a range of jobs and income opportunities, vast levels of communication and social mobility. Significantly, we have established a world that requires international relations and cooperation between different groups of people and different cultures. We are currently living at a time when human population is at its largest, over 7 billion. Society has established rural and urban facilities and services that humans have now become reliant upon for the basic needs to survive. For most humans, hunting and foraging for food is not a practice they conduct, our water is on tap, we shop in (super)markets and many have become accustomed to food being delivered to their doors ready to eat. We have become dependent on a social and global systems that supports not only our basic human needs to survive and to live longer (such as medicine and hospitals), but also new characteristic (one's we do not share with our hunter-gather ancestors), new characteristic around the concepts of pleasure and our desirability for a range of modern commodities and experiences (such as popular culture and entertainment).

Society and Homo sapiens have grown and developed into a remarkably fascinating species. Nonetheless, at present we still rely on our environment to survive (just like our ancestors). But our evolution and longevity are not guaranteed. Whilst we are adaptable and creative, we remain fragile and vulnerable. What happens if a deadly event pushes us to the edge? By some means or another (natural or manmade), a catastrophic event puts humanity on the brink of extinction? Who will remain, and what (cap)abilities will they have to operate in the natural environment? Will those left, yearn for some of the survival characteristics and skills of our ancestors; of hunter-gatherers? Could we make changes in our current lifestyle and travel experiences that would prepare us for any volatile events? The following will now present two future scenarios where humans would require the skills of our ancestral past, due to changes in our living conditions. The role of adventure tourism will then be considered.

\section{Future scenarios}

Poundstone (2019a) points out that technological optimists tell us that we have a long, populous future and that society is still evolving, with a glorious destiny in front of us. Humanity has survived many great challenges, from mammoths, malaria and atom bombs. But that does not mean we are invincible. There have been plenty of studies and ongoing research exploring how technology could propel us into the future, providing free energy on a mass scale or propelling us into the universe to explore and live on different planets. Elon Musk aims to establish human settlements on Mars within the next decade (Grossman, 2016). Cresswell et al. (2018, p. 1) explore the potential of robotics and artificial intelligence in transforming industries, environments and humans. Similar to a point echoed by Poundstone (2019b) who also recognises how future technology might change the human condition, as we become a genetically or digitally enhanced race. Maybe a different life form will present us with new opportunities. Recently, a former Israeli space security chief said 
aliens exist, and that a galactic federation has been in contact with Israel and the US for years (Reich, 2020). Likewise, religious text will have us believe that God will be our saviour, maybe not. When asking what future might become of our species, we can recall on science fiction visions or news stories on technological revolutions (such as the ideas above), which showcase humans potentially evolving in different forms (from big-brained humans with a high forehead and higher intellect, to transhumanist ideas and blended versions of Al, robotic technology and Homo sapiens mashed together).

However, another vision considers how humans are no longer evolving physically, and that technology has put an end to the "brutal logic of natural selection and that evolution is now purely cultural" (Scientific America, 2012). Or as noted, humans have tried to blend all elements together, to provide us with the best chance of survival; genes, culture and technology all driving evolution. If any of these are to be successful, remains an unknown entity and only time will tell. At present it could be suggested that our world has become somewhat confused, a planet, a social system of differing schools of thought, ideas and knowledge that present society with an overwhelming range of possibilities. What remains likely and consistent, is our society and our future can expect continued uncertainty. Therefore, it is important to present and contemplate future ideas, because, the future remains unknown.

Accepting that we could eventually die off as a species is difficult to contemplate, and for many not something they do, as they are likely to pass away before any great catastrophic event. But that does not mean society cannot prepare future generations. Being prepared for difficulty plays a significant role in how individuals and wider society copes and ultimately manages the potential level of suffering involved. The following two scenarios are based on the idea that society is on the brink of extinction (at two different times, one in the distance future and one in the near future). Following each scenario is a brief consideration / discussion on how society could end up is such a situation. Following this, the paper considers how current travel practices could provide us with better survival strategies in the event that either of the scenario becomes a future reality.

\section{Scenario 1}

Tipping point-Long drawn out change as a result of climate change and ecological collapse (around $700+$ years from now).

If humans do push our natural environment to the limits, destroying habitats and seeing the extinction of vast numbers of species, society could eventually see itself slowly drifting backwards. As large sections of the planet become unhabitable, the population of Homo sapiens over time could gradually reduce. Humans could find themselves living once again in small isolated communities around the globe. Without the communication and transportation capabilities of the past, a few hundred thousand Homo sapiens are left. Like their ancestors, these people, had to re-teach themselves how to survive in the natural environment (but had the time to do this, as the degradation of the natural world was gradual). As the global temperatures changed, migration patterns and rain fall also altered. Consequently, Homo sapiens had to leave their small communities and progressively operate more like hunter-gathers. Unlike their ancestors, they were somewhat better equipped, with greater knowledge and understanding of the global landscape and the environment. They held onto the useful inventions of the past (books and tools that allowed them to understand the land and use it to support them). However, the planet has changed, the environment is different. Whilst species exist, there are also new ones. As the last survivors of the human race, they once again became nomadic, travelling by land and boat, wandering the Earth in search of the most suitable living conditions and to develop greater understanding of how the world has changed. Every now and then meeting new communities, and the more desperate (i.e. struggling to survive) the greater level of hostility encountered. However, in some circumstances shared encounters would lead to cooperation and the sharing of ideas and resources. As the last remaining Homo sapiens, they move and travel the Earth for purposes of survival, acquiring food, water, shelter and basic resources such as new knowledge, medical provisions and tools. As with their hunter-gather ancestors, survival 
of the fittest is evident, as medicines and medical practices of the 20th and 21 st century are now tales of a great past, shared around campfires. Travel once again centres mainly on the needs for acquiring necessities for survival and to mitigate climatic conditions.

\section{Scenario 1 discussion}

It is becoming more evident and accepted that our species, Homo sapiens, has played a significant role and impact on Earth which will have lasting and potentially irreversible effects on the ecosystem, our environment and biodiversity. Whilst the start of the Anthropocene is up to debate, it's presence can be associated with what is sometimes called the Great Acceleration; a time of increased carbon dioxide emissions, global warming, ocean acidification, habitat destruction, extinction and widescale natural resource extraction which are all showing signs that humans are significantly modifying the planet (Pavid, 2021). The Anthropocene age has not been adopted, but it does offer an insight into where we currently stand as a species. "Ecosystems are the delicate community of living organisms, like humans and animals, interacting with their non-living environment, like air and water. Ecosystems can recover from a certain amount of impact from humans, like temperature increases or habitat loss, but there's a tipping point at which they cannot-and according to the report, we might be reaching that tipping point" (Higgins, 2018).

A report by a United Nations panel of scientists suggests that we only have 12 years to keep global warming to moderate levels (Intergovernmental Panel on Climate Change, 2020). Projections considering the effects of climate change vary depending on how much the Earth warms, which is usually modelled on an increase of 1-3 degree Celsius. In any case, none of the scenarios provide positive outcomes. In the best case, we are likely to see more frequent and severe tropical cyclones. Midrange predictions include the loss of most global agricultural land and freshwater sources. Such impacts could see major coastal cities like New York and Mumbai ending up underwater. In the worst-case scenario, human civilisation would come to an end (Higgins, 2018). Scenario 1 suggests that over time, due to humanities use and neglect of the natural environment, our habitats and ecosystems, which we rely on for food, water and oxygen, would slowly deplete. Over the course of the next 700+ years, ocean acidification, deforestation (and wildfires), rising sea temperatures and levels, would lead to gradual but ultimately deadly consequences to Homo sapiens. Such changes would happen in a timeframe that would not allow us to evolve to the required level to exist in our natural environment. As noted above, in this case, the solutions for nonnatural evolution did not come to our saviour. Human population over the course of $700+$ years depleted as we could no longer operate in the natural world. Our consumption of it, lead to changes that were too fast for us to adapt. Our likely extinction is now more certain than ever, as only a few hundred thousand remain.

\section{Scenario 2}

Tipping point - A sudden change as a result of natural disasters (around 70+ years from now).

In a turn of devastating events, the Earth was struck by sudden disaster(s). Within a short period (a few years) the human race was decimated, with only a few hundred thousand people still alive, scattered in small communities around the globe. The remaining Homo sapiens were suddenly deprived of the social living conditions they had become so used to. Humans were catered for at every level, with access to all the basic necessities (food, water, shelter and medicines), to accessible global communication and transport networks (for work, leisure and engaging with friends and relatives). From a global population over 9 billion, now, only a few remain. Unlike their hunter-gather ancestors who had skills and knowledge to survive in the natural environment, the "last of us" were quickly shocked into their new existence. Now the natural environment is dangerous, fierce weather patterns (excruciating heat and freezing temperatures), cyclones, drought and flooding, wildfires, volcanic eruptions (polluting the air) and earthquakes. Survival is still possible, but humans had become unaccustomed to such difficult terrain and climates. They seriously lack the required skills to operate in the volatile and hostile natural world. As humans 
became so detached from their natural environment, so did their capabilities to live from it. However, like our ancestor, Homo sapiens are once again forced to travel and migrate like nomads, seeking the basic human resources to survive. The remaining humans travel in search of food (hoping to locate some of the remaining sources of food which might have had a longer shelf live), whilst also attempting to learn how to hunt and fish for food. Travelling also offers the opportunity to seek out the last remaining medical provisions. As communities come into contact, there continues to be a mixture of hostility and cooperation. As resources are limited and the lands lawless, a combination of survival of the fittest and those who have the best tools for fighting (remaining weapons and those who have skills to make what they can off the land) quickly establish their dominance (when any such encounters occur). The chances of survival are much smaller, as the short and sudden changes as a result of increased and widespread natural disaster provided humans with less time to learn, understand and adapt to living in a hostile ecological system. Travel once again is born out of necessity and survival and is no longer a form of pleasure.

\section{Scenario 2 discussion}

The potential of a sudden natural disaster that can bring about devastating change to our environment is something scientists continue to explore. 74,000 years ago, a super volcanic explosion ejected debris into the atmosphere, that lead scientists to believe that it caused the Earth to cool by several degrees Celsius. Consequently, experts believe this event led to the greatest plant and animal extinction in human history, bringing the species to the brink of extinction (Higgins, 2018). It is difficult to predict if an event of similar magnitude can happen today, with data suggesting that a super volcanic eruption occurs on average every 17,000 years. If so, society is currently overdue (the last known one being around 26,500 years ago in New Zealand). Scientists continue to monitor several risk areas, such as Yellowstone in the US (Higgin, 2018) and the Lake Toba supervolcano on the Indonesian island of Sumatra (Froelich, 2020). Such changes to the ecosystem and climate change (as discussed in scenario 2) have the potential to lead to significant environmental change that could leave our social living conditions in the balance and could happen quickly. Such a scenario is explored by Figueres and Rivett-Carnacby (2020). The authors in a scenario called "the world we are creating", stress, if society maintains its current patterns of consuming the planet and its resources and does not reach net-zero carbon emissions, then a hostile future will soon be upon us. Their scenario paints a vivid picture of the near future, where Earth's temperature would become unbearable, with increased air pollution and coral reefs all but vanished. Rising oceans will devastate coastal communities. Whilst some humans could still live in some form of isolated safety, many will be cast to the winds, once again gathering and living in small tribes, squatted down, living and surviving on whatever patch of land will sustain them. As the authors note, the demise of the human species is a topic that is frequently considered, and at present, if we continue as we are, it is more a matter of when the end will come, not if (Figueres and Rivett-Carnacby, 2020, pp. 21-31).

Scenario 2 considers a sudden end brought about by some type of natural disaster. However, such a sudden (near) end could transpire due to other natural phenomenon or manmade disasters. Earthquakes and megathrust earthquakes can lead to tsunamis, such as the Chilean megathrust disaster apparently waiting to happen on the West Coast of Chile in South America. It is suggested that the Coquimbo region has an unusual, increasing seismicity that could see a very large earthquake before the end of the 21 st century. Such a megathrust earthquake would be accompanied by a devastating tsunami (Froelich, 2020). Other disasters could include asteroid collisions, global pandemics and plagues, biological and chemical warfare, nuclear war and disasters, solar geoengineering, artificial intelligence and potentially unknown risks that we are unaware of today (Higgins, 2018).

As noted earlier, many of the current solutions in dealing with a potential doomsday scenario are top-down and offer very little to the everyday individual. Many ideas are government / scientific community led. As many people today, especially in the Western world, would find it almost impossible to fend for themselves (in less of course they have been trained be it as outdoor experts 
or via the military). In the event of a doomsday scenario, people could be left scattered across the planet, fending for themselves. Therefore, there remains significant potential and value in revisiting the skills and characteristics of our hunter-gather ancestors and reconnecting and reigniting these within us today. Not leaving ourselves dependent on the institutions that currently support us, because, they might not be so willing or even capable when faced within unmanageable events. Thus, in any such scenario, where people are left isolated and alone, they would have built up some skills and knowledge of how to survive in the natural world.

\section{The role of adventure tourism}

What does all this mean for tourism today and in the near future and can tourism play a more active role in developing survival skills? For people reading this, scenario 2 would most likely be the more alarming to them. Because such a scenario could have implications for people living today (or at least their children and grandchildren). Scenario 2 is suggested / presented at least in this paper, as something that could happen soon (evidenced by other predictions explored above). Significantly, in the event of either scenario or something similar becoming the reality for Homo sapiens in the future, for most people, our current skill set would not see us last long in the natural world. As our current methods of living mean we have now become more detached than ever from the natural world. Rather than fending for ourselves, many would likely seek out other communities and people, and through force, would take from them, what they have-survival of the strongest. Others would be a little better prepared, as they would have lived a lifestyle that allowed them to be more accustomed to outdoor living (this is especially the case in scenario 2).

One of the overriding messages being addressed here is the cycle of life and how over time, in the case of each scenario, Homo sapiens could find themselves moving around this planet for similar purposes to our ancestors, like hunter-gathers. This paper is not suggesting Homo sapiens will experience devolution (or backward evolution), the idea that our species will revert to more primitive forms over time. Instead, humans will continue to evolve on the planet in accordance to environmental changes that take place. What is being proposed here, is that humans could move around the planet similar to the manner and motives that our ancestor assumed. Travelling like nomads in order to survive, seeking food, water, shelter, protection and discovery. Importantly, however, especially in the case of scenario 2 , most humans today, arguably lack the capacity to survive in such circumstances, especially if our planetary conditions became even more volatile (as we are being warned). As in the past, humans have the capacity to live in all types of natural environments and have shown amazing capabilities to survive in extreme conditions. But this does not mean everyone can and could do so in the event of sudden changes (especially in the event of scenario 2). If the world was to be struck by devastating events, it is not easy to predict which humans would survive and where geographically people would be. It is possible, that pockets of humans would be located around the globe.

This paper has presented two scenarios' on the extreme side of human extinction, but humans around the world today are confronted with difficulty on a daily basis, situations where people are tasked with the need to live and survive from the land around them, often as a result of unforeseen changes (manmade and natural. Thus, if the two scenarios presented here seem somewhat farfetched to the reader, then it might be that they currently live in a more comfortable and privileged society. However, even moderate changes to our natural world could bring significant changes to our current living conditions, even in the more climatically balanced parts of our globe. Likewise, slight changes could significantly impact on the vast network of food distribution and trade that we have become reliant upon. So, many of us have come to rely on the availability of food in supermarkets or at our front doors. Catch some game, prepare a fire and feed your family from scratch, can you do it, would you like to be able to?

This is where travel and tourism could offer some significant benefits to individuals who are interested in developing more outdoor skills, and ultimately, better prepare humanity for any potentially challenging times ahead. As noted, travel and tourism has evolved today into a market 
that accommodates a vast range of desires and motivations. However, as we move further into the 21 st century, could we see a greater move to more outdoor based activities. Even more so should the travel industry be making greater efforts to promote adventure-based tourism? Maybe society needs more influencers and stories that are driven to promote the explorer traveller's philosophy. According to Laing and Frost (2014) these travellers are seen as elite travellers who set out to be the first, climb the highest peaks, recreate journeys (of past explorers and ancient adventurers), trek in dangerous seasons and challenge themselves. Such travel into the unknown is seen difficult in a world that is seemingly explored and well-trodden, but there will always be a constant flow of new travellers moving around the globe. Importantly, these explorer traveller's provide inspiration for other tourists to do the same. They allow other tourists to imagine themselves to be the vanguards of exploration.

Earlier, this paper identified adventure travel segments and levels of enthusiasm and age (see Figure 1). However, the types of experiences involved in adventure travel are now considered in more detail here. Presented in Figure 2 is an original spectrum of soft and hard adventure activities. Hard adventure travel activities are often riskier and more dangerous and take place in some extreme natural environments, requiring a high level of skill set. Whilst soft activities are perceived as less dangerous and risky and often can be carried out individually, as a lower skill set is required or in some circumstances are practiced with a professional guide.

If either scenario (one or two) presented above, or something similar was to transpire, this paper stresses that humans would require similar skills demonstrated by our ancestors to be best equipped to survive. Travel would no longer exist as it does today, it would revert to more similar forms that can be seen at its origins, nomadic movements, where people would seek out new lands for purposes of food, water, shelter and the discovery of new resources and ideas. Thus, it could be argued that some forms and practices in tourism today could offer individuals the required experiences and knowledge that are more suited to our origins and potentially better prepare us if more turbulent times are ahead.

This paper suggests that adventure tourism activities are one such form. As can be seen by the (soft and hard) activities that are commonly associated with adventure tourism, many of them not only teach valuable skills for survival such as hunting and fishing, but they also take place in a range of different geographical environments and climates. Therefore, tourists who spend more time engaging with the activities presented in Figure 2, could be positioning themselves to be better equipped to deal with any sudden or more gradual changes in the natural environment; especially, changes that could result in humans being forced to live more like our nomadic (hunter-gather) ancestor, living off the land. Figure 2 offers some insight into the level and difficulty of the activities related to adventure tourism. It would be suggested, that tourists seeking to increase their survival capabilities should explore the range of activities on offer and the skills that come with them. Most tourists at present (as identified above) are likely to engage in soft activities, for short periods, often part of a wider tourism holiday. However, for those with serious intentions of developing better copying mechanism for outdoor living and survival, working towards and partaking in the hard activities would be recommended. Especially if individuals want to be better placed to sustain themselves in the event that either scenario presented here became a reality, or something similar.

Thus, it is recommend that tourism related industries and organisation make greater effort to promote and establish opportunities for people to participate in adventure based tourism. At minimum, if the doomsday scenarios' presented here do not transpire to such extreme cases, individuals participating in adventure tourism activities would still yield many benefits beyond the survival skills gained. Nature makes exercise easier and time outdoors can reduce stress, give people a sense of accomplishment, offers new challenges and increase motivation and confidence. The outdoors is our natural home and encouraging people to spend more time in it and for some to reconnect should be actively promoted by the tourism industry. 


\section{Conclusion}

"The doomsday argument pulls back the curtain on technocratic optimism. It forces us to contemplate the possibility that we, and the universe, are more random than we like to think. The fact that our species is capable of a long future does not mean this is probable. It may be something that has to be earned by being smarter, wiser, kinder, more careful-and luckier-than we've ever had to be before" (Poundstone, 2019b). Maybe now, we need to take more time than ever before to reflect on how we are progressing as a species and using foresight, asking the questions, what skills do we require in order to master our short and long-term survival.

The focus in this paper was to ask the question, is society prepared, to not only survive but live in nature in the event of a gradual or sudden decline in our environment and ecosystems; driving Homo sapiens to the brink of extinction? Two scenarios were presented, using the narrative method, each exploring the potential that our environment could eventually decline and what this would mean for Homo sapiens. The paper suggests that over the course of time (short or longterm), if society is propelled into environmental destruction, then a few hundred thousand Homo sapiens scattered around the globe are likely to travel for similar means and purposes to our hunter-gather ancestors. Additionally, the paper stresses that various skills and abilities will be required by "the last of us" on the planet in order to operate and survive in the natural world. However, due to our current industrial globalised communities, many of us are no longer capable to fend for ourselves (our social systems provide us with all our needs and requirements). However, adventure tourism and the activities connected to the industry could offer individuals with some support in recapturing some of our basic instincts and survival skills.

This paper, stresses, that adventure tourism, which is currently seen as a growing niche market, should be encouraged and promoted, as the skills and experiences associated with adventure travel could provide people with a better understanding of our natural environment. Helping people to reconnect with nature and learning to operate in different challenging conditions and environments. Many of the skills that were key to our ancestors (hunter-gathers) surviving and eventually evolving into who we are today, are skills people can experience and develop by participating in adventure tourism activities. The paper presents an original spectrum of soft and hard skills-based adventure tourism activities and recommends that these are areas that the tourism industry can look to better manage and promote in the coming years. It was also identified that the industry was already seeing positive signs of growth and the recent COVID-19 pandemic could lead to more people wanting to reconnect with nature and consequently adventure based activities. Thus, maybe individuals themselves will become increasingly motivated (due recent events such as COVID-19 sparking new enthusiasm) to acquire more outdoor skills.

Ideally, the doomsday predictions and the warning signs (including ideas presented here) should be enough for society to start considering how to improve our ourselves, the health of our natural habitats and ecosystems, striving to avoid such potentially devastating events. However, the signs and messages being poured on society around the idea of a Judgment Day event are widespread. As highlighted here in scenario 2 (based on current trends), in our lifetime, we could be living on a volatile and fragile planet. Thus, "the last of us" may be forced into an existence more reminiscent of the past. Here, society, Homo sapiens could once again (like their ancestors) be required to live off the land and move around like nomads. Of course, alternative views and future foresights could be presented. There is no guarantee of how society might develop and how Homo sapiens will evolve in the next $50+$ years. Maybe new skills will be needed that are currently unknown to us. But this paper is positioning its ideas based on the future past, the notion that the past will continue to be part of our future. In this case, the past centres on our continued basic primitive human instincts, instincts and skills that have been around for thousands of years and arguably will be for many more. Significantly, our continued relationship and dependence on the natural environment for basic resources to survive.

Thus, this paper encourages the idea that people through tourism practices should reconnect with our inner origins and seek out more adventure experiences as a means to enhance one's own sense of natural survival. Hopefully, Homo sapiens will navigate into a peaceful and prosperous 
future, in harmony with each other and Mother Nature. If not, adventure tourism should be seen as a beacon of hope, offering tourists (individuals) new outdoor experiences that can enhance their survival skills, giving Homo sapiens every chance of continued existence. The industry should continue to play an active role in providing tourists with adventure-based activities and consider how to map a vision for tourists to seek out a path of progression. Adventure tourism continues to be a niche industry much to the level and variety of skills and activities involved. For many this can be the initial obstacle to getting involved, but with more promotion and awareness people could start to harness their inner hunter-gather proficiencies.

"Other species of human used to walk the Earth. Homo sapiens are the last to survive" (Scharping, 2020).

\section{References}

Adventure Travel Trade Association (2021), "Adventure travel guide qualifications and performance standard - III. Definitions", available at: https://www.adventuretravel.biz/education/adventure-edu/guide-standards/ adventure-travel-guide-qualifications-performance-standard-iii-definitions/ (accessed 15 January 2021).

Barrett, M. (2016), "Living planet report 2016", available at: https://www.wwf.org.uk/updates/landmarkreport-shows-global-wildlife-populations-course-decline-67-cent-2020 (accessed 13 January 2021).

CBI (2021), "The European market potential for adventure tourism", available at: https://www.cbi.eu/marketinformation/tourism/adventure-tourism/adventure-tourism/market-potential (accessed 15 January 2021).

Ceballos, C., Ehrlich, P.R., Barnosky, A.D., Garcia, A., Pringle, R.M. and Palmer, T.M. (2015), "Accelerated modern human-induced species losses: entering the sixth mass extinction”, Science Advances, Vol. 1 No. 5, pp. 1-5.

Chouhan, N., Vig, H. and Deshmukh, R. (2019), Adventure Tourism Market: Opportunities and Forecasts, 2019-2026, Allied Market Research, available at: https://www.alliedmarketresearch.com/adventure-tourismmarket (accessed 16 January 2021).

Cresswell, K., Cunningham-Burley, S. and Sheikh, A. (2018), "Health care robotics: qualitative exploration of key challenges and future directions", Journal of Medical Internet Research, Vol. 20 No. 7, pp. 1-11.

Dowd, J. (2004), "Risk and the outdoor adventure experience: good risk, bad risk, real risk, apparent risk, objective risk, subjective risk", Australian Journal of Outdoor Education, Vol. 8 No. 1, pp. 69-70.

Drake, N. (2017), "Will humans survive the sixth great extinction?", available at: https://www. nationalgeographic.co.uk/environment-and-conservation/2017/10/will-humans-survive-sixth-greatextinction (accessed 13 January 2021).

Ewert, A. and Hollenhorst, S. (1989), "Testing the adventure model: empirical support for a model of risk recreation”, Journal of Leisure Research, Vol. 21 No. 1, pp. 124-136.

Figueres, C. and Rivett-Carnac, T. (2020), The Future We Choose: Surviving the Climate Crisis, Manilla Press, London.

Froelich, P. (2020), "The next mega disasters that could happen at any moment (and kill us all)", available at: https://nypost.com/2020/01/18/the-next-mega-disasters-that-could-happen-at-any-moment-and-kill-usall/ (accessed 15 January 2021).

Garrett, B. (2020), “The bunker builders preparing for doomsday”, available at: https://www.bbc.com/future/ article/20200513-the-bunker-builders-preparing-for-doomsday (accessed 10 May 2021).

Gladwell, M. (2002), The Tipping Point: How Little Things Can Make a Big Difference, Back Bay Books, Boston, M.A.

Groeneveld, E. (2016), "Prehistoric hunter-gatherer societies", available at: https://www.ancient.eu/article/ 991/prehistoric-hunter-gatherer-societies/ (accessed 13 January 2021).

Grossman, L. (2016), "The world in 2076: thousands of people have settled on Mars", available at: https:// www.newscientist.com/article/mg23231001-000-the-world-in-2076-thousands-of-people-have-settled-onmars/ (accessed 15 January 2021).

Hall, C.M. and Weiler, B. (1992), "Introduction”, in Weiler, B. and Hall, C.M. (Eds), Special Interest Tourism, London Belhaven Press, pp. 1-14.

Heijden, Van de., Brandfield, R., Burt, G., Cairns, G. and Wright, G. (2002), The Sixth Sense: Accelerating Organizational Learning with Scenario, Wiley, Chichester. 
Higgins, A. (2018), "10 ways the world is most likely to end, explained by scientists", available at: https:// www.vox.com/future-perfect/2018/10/18/17957162/nuclear-war-asteroid-volcano-science-climate-change (accessed 15 January 2021).

Hobsbawn, E.J. (1995), The Age of Extremes: The Short Twentieth Century, 1914-1991, Abacus, London. Intergovernmental Panel on Climate Change (2020), "Global warming of $1.5^{\circ} \mathrm{C}$ ", available at: https://www. ipcc.ch/sr15/ (accessed 15 January 2021).

Laing, J. and Frost, W. (2014), Explorer Travellers and Adventure Tourism, Channel View Publications, Bristol.

Lee, M. (2012), Knowing Our Future: The Startling Case for Futurology, Infinite Ideas, Oxford.

Li, X., (Robert) and Petrick, J.F. (2008), "Tourism marketing in an era of paradigm shift", Journal of Travel Research, Vol. 46 No. 3, pp. 235-244.

Lindgren, M. and Bandhold, H. (2009), Scenario Planning: The Link between Future and Strategy, Palgrave Macmillan, New York.

Lipscombe, N. (2007), "The risk management paradox for urban recreation and park manager: providing high risk recreation within a risk management context", Annals of Leisure Research, Vol. 10 No. 1, pp. 3-25.

Longrich, N.R. (2020), "Will humans go extinct? For all the existential threats, we'll likely be here for a very long time", available at: https://theconversation.com/will-humans-go-extinct-for-all-the-existential-threatswell-likely-be-here-for-a-very-long-time-135327 (accessed 13 January 2021).

Mannermaa, M. (1991), "In search of an evolutionary paradigm for futures research", Futures, Vol. 23 No. 4 , pp. 349-372.

Martin, P. and Priest, S. (1986), "Understanding the adventure experience", Journal of Adventure Education, Vol. 3 No. 1, pp. 18-21.

Miles, I. (1978), "The ideologies of futurists", in Fowles, J. (Ed.), Handbook of Futures Research, Greenwood Press, London, pp. 68-69.

National Geographic (2021), "Hunter-gatherer culture", available at: https://www.nationalgeographic.org/ encyclopedia/hunter-gatherer-culture/ (accessed 13 January 2021).

Pavid, K. (2021), "What is the Anthropocene and why does it matter?", available at: https://www.nhm.ac.uk/ discover/what-is-the-anthropocene.html (accessed 15 January 2021).

Pidgeon, N., Kasperson, R. and Slovic, P. (2003), The Social Amplification of Risk, Cambridge University Press, Cambridge.

Polkinghorne, D.E. (1998), Narrative Knowing and the Human Sciences, University of New York Press, Albany, Statue.

Poundstone, W. (2019a), “'Doomsday’ math says humanity may have just 760 Years left”, available at: https://www.wsj.com/articles/doomsday-math-says-humanity-may-have-just-760-years-left-11561655839 (accessed 13 January 2021).

Poundstone, W. (2019b), "A math equation that predicts the end of humanity", available at: https://www.vox. com/the-highlight/2019/6/28/18760585/doomsday-argument-calculation-prediction-j-richard-gott (accessed 13 January 2021).

Propper, K.R. and Miller, D. (1983), "A proof of the impossibility of inductive probability", Nature, Vol. 302 No. 5910, p. 687.

Rasmussen, I.B. (2005), "The narrative aspect of scenario building - how story telling may give people a memory of the future", Al and Society, Vol. 19 No. 2, pp. 229-249.

Reich, A. (2020), "Former Israeli space security chief says aliens exist, humanity not ready", available at: https://www.jpost.com/omg/former-israeli-space-security-chief-says-aliens-exist-humanity-not-ready651405 (accessed 15 January 2021).

Rifkin, L. (2013), "The survival of humanity", available at: https://blogs.scientificamerican.com/guest-blog/ the-survival-of-humanity/ (accessed 16 January 2021).

Ross, J. (2020), Adventure Tourism Industry Looks for a Way Forward, available at: https://www. pressandjournal.co.uk/fp/news/highlands/2647672/adventure-turism-industry-looks-for-a-way-forward/ (accessed 15 January 2021). 
Rotmans, J., van Asselt, M., Anastasi, C., Greeuw, S., Mellors, J., Peters, S., Rothman, D. and Rijkens, N. (2002), "Visions for a sustainable Europe", Futures, Vol. 32, pp. 809-831.

Sandberg, A. and Bostrom, N. (2008), Global Catastrophic Risks Survey, Technical Report 2008-1, Future of Humanity Institute, Oxford University, pp. 1-5.

Scharping, N. (2020), "When will Homo sapiens go extinct?", available at: https://www.discovermagazine. com/planet-earth/when-will-homo-sapiens-go-extinct (accessed 13 January 2021).

Schlegelmilch, F. and Ollenburg, C. (2013), "Marketing the adventure: utilizing the aspects of risk / fear / thrill to target the youth traveller segment", Tourism Review, Vol. 68 No. 3, pp. 44-54.

Scientific America (2012), "What may become of Homo sapiens", available at: https://www. scientificamerican.com/article/what-may-become-of-homo-sapiens/ (accessed 15 January 2021).

Tourism Notes (2021), "Adventure tourism", available at: https://tourismnotes.com/adventure-tourism/ (accessed 15 January 2021).

van der Tuuk, B. (2020), "History of the future of tourism", in Yeoman, I. and McMahon-Beattie, U. (Eds), The Future Past of Tourism: Historical Perspectives and Future Evolutions, Channel View Publications, Bristol, pp. 11-19.

van Notten, P.W.F., Rotmans, J., van Asselt, M.B.A. and Rothman, D.S. (2003), "An updats scenario typology", Futures, Vol. 35, pp. 423-443.

Weber, K. (2001), "Outdoor adventure tourism: a review of research approaches", Annals of Tourism Research, Vol. 28 No. 2, pp. 360-377.

Yeoman, I. and McMahon-Beattie, U. (2016), "An ontological classification of tourism futures", Paper Presented at CAUTHE 2016: The Changing Landscape of Tourism and Hospitality: The Impact of Emerging Markets and Emerging Destinations, Sydney, CAUTHE.

Yeoman, I. and McMahon-Beattie, U. (2020), The Future Past of Tourism: Historical Perspectives and Future Evolutions, Channel View Publications, Bristol.

Yeoman, I. (2012), 2050-tomorrow's Tourism, Channel View Publications, Bristol.

\section{Further reading}

Gott, J.R. III (1993), "Implications of the Copernican principle for our future prospects", Nature, Vol. 363, pp. 315-319.

\section{Corresponding author}

Daniel William Mackenzie Wright can be contacted at: dwright3@uclan.ac.uk

For instructions on how to order reprints of this article, please visit our website: www.emeraldgrouppublishing.com/licensing/reprints.htm Or contact us for further details: permissions@emeraldinsight.com 